TERRA. Revista de Desarrollo Local e-ISSN: 2386-9968

Número 8 (2021), 705-708

DOI 10.7203/terra.8.19624

IIDL - Instituto Interuniversitario de Desarrollo Local

\title{
Reseña. Metodología en el desarrollo local sostenible
}

\section{Cristina Herraiz Lizán}

Licenciada en Geografía. Doctoranda en Desarrollo Local y Cooperación Internacional (Universidad de Valencia, España)

cristina.herraiz-lizan@uv.es

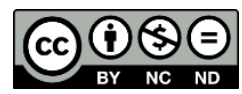

Esta obra se distribuye con la licencia Creative Commons

Reconocimiento-NoComercial-SinObraDerivada 4.0 Internacional 


\section{SECCIÓN RESEÑAS}

\section{Reseña. Metodología en el desarrollo local sostenible}

Resumen: El concepto del desarrollo local sostenible lleva entre nosotros más de tres décadas pero, en muchos casos, se hace difícil su aplicación práctica. Por ello, es necesario plantear materiales mediante los cuales los profesionales puedan diseñar planes de desarrollo y llevar al territorio los objetivos que engloban este concepto. Así, el libro "Metodologías en el desarrollo local sostenible" se plantea como una guía para introducir al lector en las técnicas más utilizadas para la elaboración de planes de desarrollo e, incluso, para el apoyo al emprendimiento en sus primeros estadios.

Palabras clave: desarrollo local sostenible, metodología, técnicas.

Recibido: 07 de enero de 2021

Devuelto para revisión: -

Aceptado: 08 de enero de 2021

\section{Referencia / Citation:}

Herraiz-Lizán, C. (2021). Reseña. Metodología en el desarrollo local sostenible. TERRA. Revista de Desarrollo Local, (8), 705-708. DOI 10.7203/terra.8.19624 


\section{Jaime de Pablo Valenciano}

\section{Miguel Ángel Giacinti Battistuzzi}

Juan Milán García

Francisco José Oliver Márquez

Juan Uribe Toril

\section{METODOLOGÍA EN EL DESARROLLO LOCAL SOSTENIBLE}

Madrid (España), Delta Publicaciones, 2018, 103 páginas

\section{D) DELITA}

\section{METODOLOGÍA EN EL DESARROLLO LOCAL SOSTENIBLE}

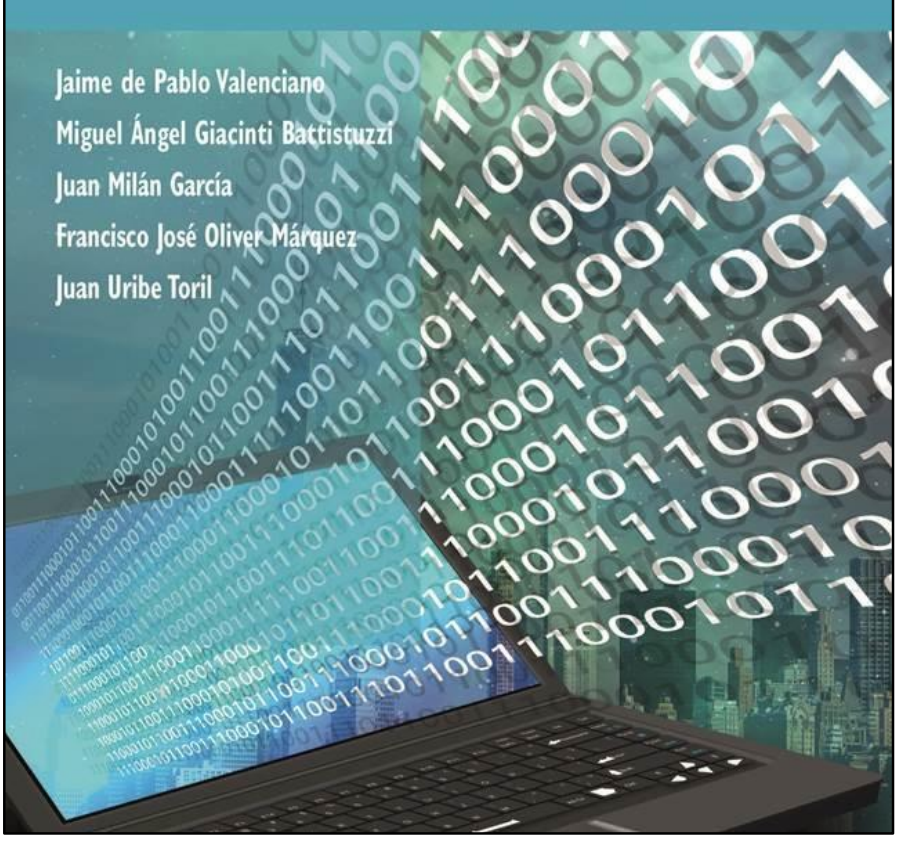

ejemplo práctico en cada una de ellas.
Existen numerosas publicaciones respecto a los diferentes enfoques del desarrollo sostenible, pero no se encuentran tantas acerca de aquellas técnicas que se pueden aplicar durante el proceso de planificación y desarrollo de un plan de desarrollo sostenible.

Por ello, "Metodología en el desarrollo sostenible" se plantea como un breve libro en el cual se resumen aquellas técnicas más utilizadas por los expertos. De esta manera, el lector puede conocer las diferentes herramientas de una forma rápida para, posteriormente, profundizar en las que crea conveniente mediante otros manuales.

Así, este libro es especialmente interesante para aquellas personas que se comiencen a explorar el mundo del desarrollo local, ya que explica brevemente cada técnica $\mathrm{y}$, de una manera muy didáctica, se desarrolla un

Para facilitar su lectura, el libro se encuentra dividido en tres bloques. El primero de ellos hace referencia a las metodologías de diagnóstico. En él podemos encontrar cinco técnicas diferentes: i) el método PIN, que se utiliza para evaluar una idea contemplando sus puntos positivos, negativos e interesantes; ii) el método ETPO, similar al DAFO pero en el que se incluye la valoración del tiempo (pasado y futuro); iii) el globo volador, una técnica enfocada más al trabajo de diagnóstico con la población local para determinar diferentes aspectos (territorios competencia, instituciones, obstáculos, etc.); iv) el análisis PESTEL (Políticos, Económicos, Sociales, Tecnológicos, Ecológicos y Legislativos), más indicado para conocer el entorno exterior de una organización; v) y, por último, el método CANVAS, el cual ayuda a organizar una idea de negocio en ciertas partes clave. 
El segundo bloque se corresponde con las metodologías de análisis estratégico. La primera trabaja la "Agenda Competitiva", donde se combinan actores privados e instituciones públicas para ejecutar un plan sectorial. También se presenta el "Plan General de Negocios", el cual presentan los autores como una manera diferente de trabajar el desarrollo local. Como no podía faltar en un libro de estas características, el "Enfoque del Marco Lógico" también se encuentra entre las técnicas explicadas. Y, para acabar con la parte analítica, se presenta el "Análisis Estratégico Sistémico", el cual utiliza el análisis de sistemas para la comprensión del territorio.

El último bloque se corresponde a la recogida y tratamiento de los datos. Respecto a la recogida de datos, primero se explican las partes fundamentales de un estudio de caso y, como segunda técnica, se exponen las experiencias de campo o metodología de la sistematización de experiencias. En cuanto al tratamiento de datos, se comentan diferentes metodologías de clasificación como el análisis clúster, clúster jerárquico, clúster no jerárquico y árboles de clasificación. Para acabar, se presenta el enfoque del marco Input-Output para el análisis sectorial.

Como manifestamos en esta sucinta reseña, el libro dispone de una serie de técnicas con objetivos muy variados y diversos, las cuales no pueden ser sustitutorias entre ellas, sino que se presentan más bien como técnicas complementarias. Asimismo, no solo se concibe este libro como una guía para la elaboración de un plan de desarrollo local sino también, como herramienta para los Agentes de Desarrollo Local/Territorial que necesiten ayudar a emprendedores en las fases iniciales de sus proyectos.

Cristina Herraiz-Lizán

Licenciada en Geografía. Doctoranda en Desarrollo Local y Cooperación Internacional (Universidad de Valencia) 